\title{
MATTER

\section{Review of the book: Derrida after the End of Writing. Political Theology and New Materialism, Perspectives in Continental Philosophy (Crockett, Clayton, 2018)}

\section{Rocco Monti \\ University of Milan}

\section{DOI: https://doi.org/10.1344/jnmr.v2i2.35903}

The intention of this book is not to provide a detailed exposition of Derrida's deconstructionist philosophy, but rather to move, through Derrida's late writings, towards new philosophical horizons such as speculative realism, 000 (objectoriented-ontology) and new materialism. This text consists of eight chapters. Each of them would deserve a long discussion because of the vastness of topics and references Crockett touches upon. To sum up the aims of this book, we can say that Crockett understands Derrida's later philosophy from a new materialist perspective that deals with religion, ethics and politics albeit he never used the term "materialism". In doing so, the author enriches Derrida's reflections with various interactions of other authors who have contributed to and influenced the Algerian philosopher's thought. There are constant references to the continental hermeneutic-phenomenological tradition of Husserl, Heidegger, Sartre, Levinas. But there is also a comparison with contemporary authors who push Derrida even further, such as Malabou, Meilassoux, Morton and Barad. Thus, I would like to focus on the seventh and eighth chapters, in which Crockett offers an innovative interpretation of Derrida's thought from a new materialist perspective dealing with Malabou's biological materialism and Barad's quantum physical materialism. These authors help us to read deconstruction as a form of materialism, offering a framework within which Sciences and Humanities can interact and cooperate.

The new materialism is a matter of energy; or better, it is a new way of conceiving energy, on the one hand, renouncing to outline it as a sterile empiricism of pure 
difference and, on the other hand, pulling it out of a simple deterministic and mechanistic ground. This new materialism is to be configured as a transit of energy, as a dynamic system of dissipative structures. Energy is entirely material and spiritual and delineates a monist framework that does not, however, renounce transformation, qualitative mutation and the pluralism of emerging properties. This new materialism offers resources to think about matter in a dynamic and relational sense and not in a static, reductionist and atomistic way. According to Crockett,

Derrida certainly kept a critical distance from materialism; he does not use this term in a positive sense. At the same time, I think that the nonreductionist materialism expressed in terms of New Materialism offers important tools to understand Derrida. In some ways, I am appropriating Derrida as a new materialist, but I don't think that deconstruction proscribes such an entanglement. (2018, p. 8)

In the seventh chapter, Crockett deeply analyzes Malabou's notion of plasticity in connection with writing: the shift from writing to plasticity is a change consonant with the new materialisms insofar as it emphasizes the self-organizing, adaptive aspects of matter itself as a paradigm by which to overcome long-held constructed binaries between nature and culture, human and nonhuman. In this sense, plasticity allows us to see the event in the mechanism, the spirit in the material, without it thereby ceasing to be material. The concept of plasticity is extremely dialectic since, on the one hand, it embodies the essence in malleable and material forms and, on the other, it allows the schema to be identified in a series of material embodiments. With Malabou's words, "plasticity appears as a process where the universal and the particular mutually inform one another, and their joint outcome is that particularity called the exemplary individual" (2004, p. 13). Thus, the notion of plasticity outlines a biological materialism by emphasizing forms, understood as theoretical frameworks which straddle several research fields and highlight the embodied, embedded, relational and affective interconnections across human and non-human entities. On this, this book is a perfect example of the relational nature of knowledge, as it delves into various fields of research, from biology to religion, from politics to quantum physics. 
Derrida works with and through the paradoxical tension between the machinic repetition and the singular dignity of life as ethical responsibility to the other, whereas Malabou wants to unify both in her conception of plasticity. Derrida's later work thus appears more ungrounded, and he would resist adopting Malabou's characterization of this new motor scheme, but her idea of plasticity gives us a vantage point from which to make Derrida's philosophy more coherent, even if it betrays some of the letter of his writings. (2018, p. 112)

Plasticity involves both the capacity to receive form and the capacity to give form and takes place between shaping of form and destruction of that form itself. Destruction of form is an intrinsic part of the process of formation: plasticity is destructive, but this destructive nature of plasticity is not simply negative. Therefore, it is also metamorphic.

In the eight chapter, Crockett deals with Karen Barad's perspective, entangling philosophy with quantum physics. As Crokett says,

my turn to the work of Karen Barad here is not meant to invalidate the significance of biology or to undermine the importance of Malabou's philosophy, but to offer another displacement, a nontransferential clinic of quantum physics where a quantum Derrida operates. $(2018$, p. 121)

The meeting point between Crockett's interpretation of Derrida and Barad's philosophy of science lies in the fact that Crockett believes that "writing has to do with spacing, deferral, and delay and so it is what prevents full self- presence" $(2018, p .17)$ and, at the same time, Barad thinks that "there is a deep sense in which we can understand diffraction patterns - as patterns of difference that make a difference - to be the fundamental constituents that make up the world" (2007, p. 72). Barad uses Derrida's philosophy to make sense of reality at the subatomic level. In fact, like différance, quantum field theory involves both the dynamic temporization of time and space and 
a dynamic deferral as polemical opposition to identity because it involves the creation and destruction of virtual particles, which extends to take into account all of reality. Barad calls this movement diffraction: in this process waves meet and interact, forming new entities.

She argues that Derrida's philosophy offers a better way to understand this situation than many of the interpretations supplied by quantum physicists. Words, concepts, phenomena are entangled in complex ways, and deconstruction attends to the manner in which such phenomena are spookily entangled. This is a materialism of a sort, but a very strange kind of materialism, that Barad calls a hauntological materialism. Our entangled intra-actions as large slow beings repeat in a different way the relations among subatomic particles. We come to face our past lives and previous historical figures as ghosts, exerting a hauntological influence on the present. (2018, p. 130)

The world, Barad states, is an open process of mattering through which mattering itself acquires meaning and form through the realization of different agential possibilities. For this reason, "reality is therefore not a fixed essence. Reality is an ongoing dynamic of intra-activity. To assert that reality is made up of phenomena is not to invoke one or another form of idealism. On the contrary, phenomena are specific material configurations of the world" (2007, p. 206). Objects are not static things, but dynamic processes that change in their interaction and intra-action with other objects: dynamics is not what happens between things, but how these things become what they are as they transform themselves and their objects in a mutual asymmetrical process of materialization. Even if Barad does not mention Derrida in her book, she develops her notion of diffraction in a manner strikingly similar to the Derridean différance since diffraction is an ethico-onto-epistemological matter. According to Barad,

we are not merely differently situated in the world; "each of us" is part of the intra-active ongoing articulation of the world in its differential mattering. 
Diffraction is a material-discursive phenomenon that challenges the presumed inherent separability of subject and object, nature and culture, fact and value, human and nonhuman, organic and inorganic, epistemology and ontology, materiality and discursivity. (2007, p. 381)

In conclusion, this book is an important contribution to a re-reading of Derrida's thought in a new materialistic perspective and offers ideas for expanding his philosophy to a relational ontology of differences that remains faithful in some respects to the legacy of deconstruction. This proposal develops a plurality of alternative paths to the usual theological and political interpretations of Derrida's thought, reconfiguring Derrida's philosophy in a scientific context, close to quantum physics and biology. As the author himself states, "There is no proper Derrida, but there are more interesting, relevant, and compelling iterations of Derrida's thought" (2018, p.138)

\section{Bibliography}

Barad Karen, (2007). Meeting the Universe Halfway. Quantum Physics and the Entanglement of Matter and Meaning, Duke University Press, Durham.

Crockett Clayton, (2018). Derrida after the End of Writing. Political Theology and New Materialism, Perspectives in Continental Philosophy, Fordham University Press, New York 2018, p. 138.

Malabou Catherine, (2004). The Future of Hegel: Plasticity, Temporality and Dialectic, Routledge, London. 


\section{Author Information}

Rocco Monti (rocco.monti@studenti.unimi.it)

Rocco Monti is a MA graduate philosophy student at University of Milan. He wrote his MA thesis on Josiah Royce's and Charles S. Peirce's pragmatism, focusing his research on the concept of experience and the role of practices of interpretation. His areas of research concern pragmatism (Charles S. Peirce, Josiah Royce, John Dewey) and phenomenology (Edmund Husserl, Jacques Derrida). His approach seeks to integrate these two perspectives by highlighting their points of contact and elements of difference. He is currently working on the concept of vagueness (in particular in Peirce's semiotics), trying to understand how it can interact with Royce's ethical and social philosophy and how it can help to think about the genesis and articulation of values. 